\title{
Bisphosphonates and glucocorticoid-induced osteoporosis: implications for patients with respiratory diseases
}

\author{
Simone Cowan, Suzanne Morin, Pierre Ernst
}

Osteoporosis is a well known consequence of glucocorticoid treatment that can result in significant morbidity and mortality. ${ }^{1-4}$ Glucocorticoid-induced bone loss occurs early, usually within 6-12 months of starting therapy. During this time the rate of bone loss is rapid before decreasing or reaching a plateau. ${ }^{124}$ Clinically this decrease in bone mineral density puts patients at an increased risk of fracture. ${ }^{1245}$ Specifically, with a decline in bone mass of one standard deviation below the mean for young adults, the risk of fracture doubles. ${ }^{5}$ Characteristically, glucocorticoid-induced osteopenia and osteoporosis occur at a faster rate in trabecular bone; consequently, the ribs and vertebrae are common sites of fracture, although hip fractures have also been reported. ${ }^{67}$ As long term treatment with oral glucocorticoids is a common practice in the management of patients with chronic respiratory diseases, strategies to decrease the burden of glucocorticoid-induced osteoporosis are needed.

Glucocorticoid-induced bone loss results from a decrease in bone formation due to reduced intestinal calcium absorption, increased urinary calcium excretion, and reduced osteoblast formation and function. ${ }^{1248}$ The bisphosphonates, a class of drugs structurally similar to pyrophosphate, alter the bone remodelling process. By binding to hydroxyapatite these agents structurally inhibit osteoclastic activity and prevent bone resorption. ${ }^{9}$ This significantly increases bone mineral density in the lumbar spine and femur and decreases the rate of fracture at these sites. ${ }^{10-13}$ For this reason, bisphosphonates such as etidronate and alendronate have received official approval for the treatment and prevention of postmenopausal osteoporosis in many countries. The bisphosphonates have also been studied in the prevention and treatment of glucocorticoidinduced osteoporosis.

In this issue of Thorax Pitt et al shed further light on the use of etidronate for the treatment of glucocorticoidinduced osteoporosis. ${ }^{14}$ Using a double blind, placebo controlled design, patients receiving oral glucocorticoids for at least six months were randomised to receive etidronate $400 \mathrm{mg}$ daily or placebo for 14 days followed by 76 days of calcium and vitamin $\mathrm{D}$ supplementation. This three month cycle was repeated eight times over a two year period. In the primary measure of outcome a significant difference between etidronate and placebo was found in the mean percentage change from baseline in the lumbar spine after two years. Specifically, after six months there was a mean increase of $4.33 \%$ in the bone mineral density of the lumbar spine for the etidronate group which increased to $5.12 \%$ at two years. In contrast, no clinically important changes were reported in patients receiving placebo. ${ }^{14}$

A particular strength of this clinical study is that it represents one of the few trials using a randomised, double blind, placebo controlled design to show the efficacy of a bisphosphonate in glucocorticoid-induced osteoporosis for a study population consisting largely of patients with chronic respiratory disease, mainly asthma. Previous investigations have been conducted predominantly in patients with rheumatoid arthritis where the absolute risk of bone loss may be unique due to additive effects from the underlying disease process and differences in the cumulative glucocorticoid dose. ${ }^{2}{ }^{15}$ Moreover, epidemiological studies enrolling patients with respiratory diseases to assess the use of etidronate in glucocorticoid-induced osteoporosis have used non-randomised ${ }^{16-18}$ or unblinded ${ }^{161819}$ designs, short follow up periods, ${ }^{19}$ and historical controls. ${ }^{18}$ By demonstrating the usefulness of etidronate for treating glucocorticoid-induced osteoporosis, Pitt et al have confirmed the results of this preliminary research.

Unfortunately, the study by Pitt et al lacked sufficient power to translate the primary efficacy measure of bone mineral density into a clinical measure of effectiveness such as a decrease in the rate of fracture. ${ }^{14}$ These investigators were also unable to find significant treatment differences in bone mineral density of the trochanter or femoral neck, as in a previous study of glucocorticoid-induced osteoporosis. ${ }^{17}$

It is noteworthy that $60.9 \%$ and $47.5 \%$ of the screened population in the study by Pitt et al met the WHO definition for osteoporosis of the hip and spine, respectively. ${ }^{14}$ This finding underlines the necessity for preventive therapies. The bisphosphonates have also shown favourable results in the prevention of glucocorticoid-induced osteoporosis. Diamond et al reported that cyclical etidronate prevented glucocorticoid-induced bone loss of the lumbar spine and femoral neck in postmenopausal women commencing glucocorticoids for the first time or recommencing therapy. ${ }^{18}$ In a recent double blind, placebo controlled trial by Adachi et al, ${ }^{20}$ a significant difference in the mean percentage change from baseline in the bone mineral density of the lumbar spine $(3.72 \%)$ and trochanter $(4.14 \%)$ was detected between patients randomised to receive cyclical etidronate or placebo. Patients recently starting treatment with glucocorticoids maintained their bone mineral density of the lumbar spine and trochanter when randomised to receive preventive therapy with etidronate; in contrast, those in the placebo group experienced a $3.23 \%$ and $2.74 \%$ decrease from baseline, respectively. Furthermore, significantly fewer postmenopausal women receiving etidronate sustained vertebral fractures. ${ }^{20}$

Other bisphosphonates have also been studied for use in the prevention of glucocorticoid-induced osteoporosis. In the combined results of two 48 week, multinational, randomised, double blind trials, alendronate significantly increased the bone mineral density of the spine and hip relative to baseline and placebo. ${ }^{21}$ Moreover, in postmenopausal women a lower incidence of vertebral fractures occurred with alendronate. Additionally, alendronate has been investigated for the prevention of glucocorticoidinduced osteoporosis in patients with sarcoidosis by Gonnelli et $a l^{2}$ who found a significant difference from placebo in the mean percentage change from baseline in the bone mineral density of patients randomised to receive alendronate. Lastly, intravenous pamidronate has shown promising results in preventing bone loss in patients initiating glucocorticoid therapy. ${ }^{23}$

The next question to be answered is whether any particular oral bisphosphonate is truly safer and more effective in preventing and treating glucocorticoid-induced osteoporosis. Until the publication of larger clinical trials with longer follow up periods the answer to this question 
will remain unclear. Both etidronate and alendronate have now been shown to decrease vertebral fractures in postmenopausal women being treated with glucocorticoids. ${ }^{20}{ }^{21}$ In terms of safety, as a class, bisphosphonates are generally well tolerated. Alendronate has been associated with oesophagitis and oesophageal ulcers in a small percentage of patients, particularly if not taken according to the manufacturer's recommendations. ${ }^{24}$ Bone histomorphometry was found to be normal in patients treated with both continuous alendronate ${ }^{24}$ and intermittent cyclical etidronate. ${ }^{24}$ Currently, etidronate has received approval in Britain for the treatment and prevention of glucocorticoid-induced osteoporosis; therefore, pending the publication of results from ongoing alendronate studies, it would be prudent to use intermittent etidronate therapy for this indication.

It is suggested that a preventive strategy be adopted for all patients with respiratory disease initiating chronic oral glucocorticoids; this strategy should also be applied to patients already receiving chronic oral glucocorticoids with the goal of preventing further bone loss. Consensus guidelines have been published for the prevention and treatment of glucocorticoid-induced osteoporosis ${ }^{26}{ }^{27}$; however, in view of the aforementioned new information and the criticism received for some of these recommendations, ${ }^{28-31}$ we propose the following strategy. Firstly, known and potential risk factors for osteoporosis should be modified-this includes maximising the use of inhaled glucocorticoids in asthma, using the lowest possible dose of the oral glucocorticoid, initiating exercise and smoking cessation programmes, and ensuring the appropriate intake of calcium and vitamin D. Secondly, baseline bone mineral density of the lumbar spine should be measured in all high risk patients, preferably using dual energy $x$ ray absorptiometry. This measurement will serve to monitor the efficacy of the preventive strategy. Thirdly, postmenopausal women should be offered hormone replacement therapy first as it may confer cardiovascular benefits in addition to its protective effect on bone. When hormone replacement therapy is contraindicated or deemed undesirable, alendronate or intermittent cyclical etidronate should be considered. Lastly, in men and premenopausal women in whom hypogonadism is present, it should be corrected first and intermittent cyclical etidronate should then be considered. However, it is still unclear how long these patients should be treated with a bisphosphonate, particularly premenopausal women. Furthermore, the potential risk to the fetus must be considered in women of childbearing potential.

In conclusion, osteoporosis and its resulting fractures are deleterious consequences of glucocorticoid therapy. As these medications have become a mainstay in the pharmacotherapy of several respiratory diseases, the primary prevention of bone loss in high risk patients is warranted. With the emergence of clinical studies demonstrating the usefulness of the bisphosphonates for increasing and preserving bone density and preventing vertebral fractures, clinicians are now well equipped to reduce the morbidity associated with glucocorticoid-induced osteoporosis in patients with respiratory diseases.

Respiratory Epidemiology Unit,

SIMONE COWAN

Department of Epidemiology and Biostatistics,

McGill University,

Montreal,

Quebec H3A 1A3,

Canada

SUZANNE MORIN

Department of Medicine,

McGill University Health Centre,

Montreal,

Quebec H3G $1 A 4$

Canada
Division of Respiratory Medicine,

McGill University Health Centre,

Montreal,

Quebec H3G 1A4,

Canada

1 Adachi JD, Bensen WG, Hodsman AB. Corticosteroid-induced osteoporosis. Semin Arthritis Rheum 1993;22:375-84.

2 Reid IR. Glucocorticoid osteoporosis: mechanisms and management. Eur $\mathcal{F}$ Endocrinol 1997;137:209-17.

3 Hawker GA. The epidemiology of osteoporosis. F Rheumatol 1996;23(Suppl 45):2-5.

4 Sambrook PN. Corticosteroid induced osteoporosis. F Rheumatol 1996; 23(Suppl 45):19-22.

5 Scientific Advisory Board, Osteoporosis Society of Canada. Clinical practice guidelines for the diagnosis and management of osteoporosis. Can Med guidelines for the diagnosi

6 Adinoff AD, Hollister JR. Steroid-induced fractures and bone loss in patients with asthma. $N$ Engl F Med 1983;309:265-8.

7 Cooper C, Coupland C, Mitchell M. Rheumatoid arthritis, corticosteroid therapy and hip fracture. Ann Rheum Dis 1995;54:49-52.

8 Suzuki Y, Ichikawa Y, Saito E, et al. Importance of increased urinary calcium excretion in the development of secondary hyperparathyroidism of patients under glucocorticoid therapy. Metabolism 1983;32:151-6.

9 Hodsman A, Adachi J, Olszynski W. Use of bisphosphonates in the treatment of osteoporosis. Can Med Assoc f 1996;155:945-8.

10 Meunier PJ, Confavreux E, Tupinon I, et al. Prevention of early postmenopausal bone loss with cyclical etidronate therapy (a double-blind, placebocontrolled study and one year follow up). F Clin Endocrinol Metab 1997;82: 2784-91.

11 Herd RJ, Balena R, Blake GM, et al. The prevention of early postmenopausal bone loss by cyclical etidronate therapy: a 2 -year double-blind, placebocontrolled study. Am 7 Med 1997;103:92-9.

12 Harris ST, Watts NB, Jackson RD, et al. Four year study of intermittent cyclic etidronate treatment of postmenopausal osteoporosis: three years of blinded therapy followed by one year of open therapy. Am f Med 1993;95: 557-67

13 Liberman UA, Weiss SR, Broll J, et al. Effect of oral alendronate on bone density and the incidence of fractures in postmenopausal osteoporosis. $N$ Engl f Med 1995;333:1437-43.

14 Pitt P, Li F, Todd P, et al. A double blind placebo controlled study to determine the effects of intermittent cyclical etidronate on bone mineral density in patients on long term oral corticosteroid treatment. Thorax 1998;53: 351-6.

15 Verhoeven AC, Boers M. Limited bone loss due to corticosteroids; a systematic review of prospective studies in rheumatoid arthritis and other systematic review of prospective studies in
diseases. F Rheumatol 1997;24:1495-503.

16 Struys A, Snelder AA, Mulder H. Cyclical etidronate reverses bone loss of the spine and proximal femur in patients with established corticosteroidthe spine and proximal femur in patients with estab
induced osteoporosis. Am $\mathcal{F}$ Med 1995;99:235-42.

17 Adachi JD, Cranney A, Goldsmith CH, et al. Intermittent cyclic therapy with etidronate in the prevention of corticosteroid induced bone loss. $\mathcal{F}$ Rheumatol 1994;21:1922-6.

18 Diamond T, McGuigan L, Barbagallo S, et al. Cyclical etidronate plus ergocalciferol prevents glucocorticoid-induced bone loss in postmenopausal women. Am F Med 1995;98:459-63.

19 Worth H, Stammen D, Keck E. Therapy of steroid-induced bone loss in adult asthmatics with calcium, vitamin $\mathrm{D}$, and a diphosphonate. $A m \mathcal{F}$ Respir Crit Care Med 1994;150:394-7.

20 Adachi JD, Bensen WG, Brown J, et al. Intermittent etidronate therapy to prevent corticosteroid-induced osteoporosis. N Engl f Med 1997;337:382-

21 The Alendronate Corticosteroid Study Group. Alendronate for the prevention and treatment of corticosteroid-induced osteroporosis:results of the combined US and multinational studies. Merck Research Laboratories, 1997

22 Gonnelli S, Rottoli P, Cepollaro C, et al. Prevention of corticosteroidinduced osteoporosis with alendronate in sarcoid patients. Calcif Tissue Int 1997;61:382-5.

23 Boutsen Y, Jamart J, Esselinckx W, et al. Primary prevention of glucocorticoid-induced osteoporosis with intermittent intravenous pamidronate: a randomized trial. Calcif Tissue Int 1997;61:266-71.

24 Jeal W, Barradell LB, McTavish D. Alendronate. A review of its pharmacological properties and therapeutic efficacy in postmenopausal osteoporosis. Drugs 1997;53:415-34.

25 Ott SM, Woodson GC, Huffer WE, et al. Bone histomorphometric changes after cyclic therapy with phosphate and etidronate disodium in women with postmenopausal osteoporosis. F Clin Endocrinol Metab 1994;78:968-72.

26 American College of Rheumatology Task Force on Osteoporosis Guidelines: Recommendations for the prevention and treatment of Guidelines: Recommendations for the prevention and treatment
glucocorticoid-induced osteoporosis. Arthritis Rheum 1996;39:1791-801. 7 Eastell R. Management of corticosteroid-induced osteoporosis. F Intern Med 1995;237:439-47.

28 Schwartz HA. Measurement of bone density: comment on the American College of Rheumatology recommendations for the prevention and treatment of glucocorticoid-induced osteoporosis. Arthritis Rheum 1997;40: 1551

29 Fudman EJ. Lack of efficacy of calcitonin in preventing glucocorticoidinduced bone loss: comment on the American College of Rheumatology recommendations for the prevention and treatment of glucocorticoidinduced osteoporosis. Arthritis Rheum 1997;40:1549.

30 Buyon JP, Dooley MA, Meyer WR, et al. Recommendations for exogenous estrogen to prevent glucocorticoid-induced osteoporosis in premenopausal women with oligo- or amenorrhea: comment on the American College of Rheumatology recommendations for the prevention and treatment of glucocorticoid-induced osteoporosis. Arthritis Rheum 1997;40:1548-9.

31 Lukert BP, Kipp D, Broy S. Management of glucocorticoid-induced osteoporosis-first, do no harm: comment on the American College of osteoporosis-first, do no harm: comment on the American College of
Rheumatology recommendations for the prevention and treatment of glucocorticoid-induced osteoporosis. Arthritis Rheum 1997;40:1548. 